\title{
Influence of Embedded depth on mechanical behavior of micro-pile com- posite structure
}

\author{
Q. CAI, S.W. SHI , Q.K. LI\&X.Q. HAN
}

Technical Center for Geological Hazard Prevention and Control, CGS, Chengdu, Sichuan, China; Institute of Exploration Technology, CGS, Chengdu Sichuan, China

KEYWORD: $\mathrm{FLAC}^{3 \mathrm{D}}$; ;embedded depth; micro-pile composite structure ;bending and shearing failure ABSTRACT: At the two embedded solid depth, research on the displacement, bending moment and shear stress of micro-pile composite structure have been studied based on the FLAC ${ }^{3 \mathrm{D}}$ program. Results show that: micro pile maximum bending moment occurs in the vicinity of the sliding surface, the maximum shear stress at the position of the sliding surface about $1 / 8$ or more, when the micro-pile composite structure designed, need to near the surface of pile are reinforced. Embedded depth and free segment length ratio of 1:3, the displacement, shear stress and bending moment of micro-piles are relatively small, micro-pile composite structure can bear greater landslide thrust. micro-pile composite structure in the governance of sliding bed for bedrock and soil landslides, the main failure mode is near the sliding surface of the pile when bending and shearing failure occurs.

\section{INTRODUCTION}

Embedded depth is one of the important indexes of micro-pile composite structure important evaluation projects. At present, the mechanical properties of the micro pile on basic research without considering the impact of embedded depth. Such as Sun Shuwei ${ }^{[1]}$ has studied on the anti-sliding characteristics of micro-piles with cap beam, which was shown that,micro-piles with cap beam was trapezoidal distribution, and the resistance force below sliding surface was inverted with triangular distribution. The soil pressure value was larger at micropile head and around sliding surface and smaller at the bottom of micro piles. The ratio of pushing force acting on the micro-piles between the rear row and leading row was $1: 0.6$. A series of model tests of micro piles and slopes were carried out by Zhu Baolong ${ }^{[2]}$, which showed that the horizontal displacement of slopes with micro-piles reinforced is smaller than that of the bare slope, and the smaller the pile spacing,the smaller the horizontal displacement of slope.The bending moment on the pile is complicated nonlinear relationship with time, the bending moment value decreases monotonically from positive to negative, the changes in the gradient moment decreases with time. The anti-sliding characteristics of single double-row and composite anti-slide micro piles are studied by $\mathrm{Hu} \mathrm{Yifu}{ }^{[3]}$, find there are three failure models namely bending failure of the pile body,disengaging between pile and soil and the fracture failure of piles. The crack angle of single double-row piles, with bending-tensile failure, is bigger value of $65.7^{\circ}$, while the value of composite piles is $33.9^{\circ}$, with bending-shearing failure. And the backward piles cracks are more obvious than the forward piles. The soil pressure acting on the free section of single double-row pile body is "S" shaped distribution. The backward piles bear bigger soil pressure owing to directly contacting loads; meanwhile, the ratios of the maximum of soil pressure between the forward piles and backward piles are $0.53: 1-0.50: 1$. There are other scholars have also studied the mechanical properties of micro-pile, such as Zhang Dandan ${ }^{[4]}$, Feng Jun ${ }^{[5]}$, Liang Jiong ${ }^{[6]}$, Xin Jianping $^{[7]}$ through the model test of stress and deformation and failure of the research on the characteristics of the micro pile.

In order to study the influence of embedded depth on mechanical behavior of micro-pile composite structure , using FLAC ${ }^{3 \mathrm{D}}$ program, under fixed depth study of two inlay, a combination of antislide micro pile displacement, bending moment and shear stress variation. 


\section{ESTABLISH FLAC3D MODEL}

\section{Model Size}

Landslide model for bedrock and sliding body, which size of bedrock is $4.8 \mathrm{~m}$ (long) $\times 2.4 \mathrm{~m}$ (wide) $\times 1.20 \mathrm{~m}$ (high), the sliding body size is $3.6 \mathrm{~m}$ (long) $\times 2.4 \mathrm{~m}$ (wide) $\times 1.8 \mathrm{~m}$ (high), as shown in Figure 1 .

Single micro pile with steel pipe filling cement mortar, pile diameter of $3 \mathrm{~cm}$, a combination of anti-slide pile micro-miniature pile consists of four rows, each row has 10 single pile, pile spacing $22.5 \mathrm{~cm}$, each row of horizontal spacing also for $22.5 \mathrm{~cm}$, pile with $\mathrm{C} 20$ concrete coupling beams. Numerical simu-lation of 1 , the embedded depth $0.72 \mathrm{~m}$, free segment length is $1.8 \mathrm{~m}$ (block solid section and free segment length ratio of 1:2.5); simulation 2, the embedded depth of $0.6 \mathrm{~m}$, free segment length is $1.8 \mathrm{~m}$ (block solid section and free segment length ratio of 1:2.5). From the left side of the $\mathrm{C}$ model of the landslide, the row piles were named first, four and two or three rows respectively.

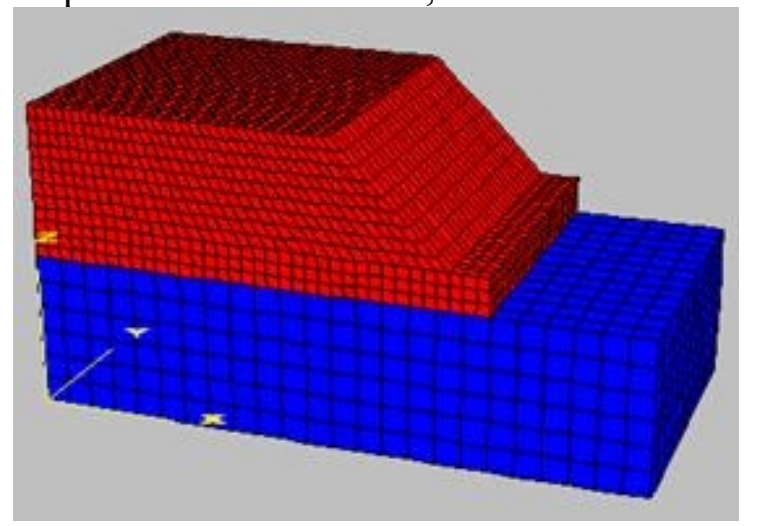

Figure 1.Numerical simulation model

\section{Constitutive relations}

Numerical model selection Mohr-Coulomb, the model is applicable to cement loose granular material to study the mechanical properties of ordinary soil and rock, constitutive relation parameters shown in Table 1.

Table 1. Constitutive material model calculation parameters

\begin{tabular}{|c|c|c|c|c|}
\hline $\begin{array}{l}\text { Parameters } \\
\text { Material }\end{array}$ & $\begin{array}{l}\text { Shear } \\
\text { Modulus } \\
\text { (pa) }\end{array}$ & $\begin{array}{r}\text { Cohesion } \\
\text { (pa) }\end{array}$ & Friction angle & $\begin{array}{l}\text { Density } \\
\mathrm{Kg} / \mathrm{m}^{3}\end{array}$ \\
\hline Landslide & $3.6 \mathrm{e} 6$ & $19 \mathrm{e} 3$ & 35 & 1680 \\
\hline Bedrock & $7.2 \mathrm{e} 6$ & $38 \mathrm{e} 3$ & 40 & 1800 \\
\hline
\end{tabular}

\section{Structural units}

Numerical model of micro piles and pile top beams are associated with the program were used FLAC $^{3 \mathrm{D}}$ pile unit and beam element to simulate specific calculation parameters in Table 2.

Table 2.Structural unit calculation parameters

\begin{tabular}{ccccc}
\hline & Parameters & $\begin{array}{c}\text { Elastic Mod- } \\
\text { ulus } \\
\text { Material }\end{array}$ & Poisson's ratio & $\begin{array}{c}\text { Cross-section } \\
\left(\mathrm{m}^{2}\right)\end{array}$ \\
\hline & Piles unit & $6.18 \mathrm{e} 10$ & 0.25 & $2.82 \mathrm{e}-3$ \\
& Beam unit & $9 \mathrm{e} 10$ & 0.27 & 0.126 \\
\hline
\end{tabular}

\section{Slip surface unit}

FLAC $^{3 \mathrm{D}}$ provided can slide, you can pull or cut interface combined with Coulomb slip, sliding surface of the model by setting the contact surface to achieve specific parameters are as follows in Table 3 
Table 3 Slip surface material calculation parameters

\begin{tabular}{ccccc}
\hline Parameters & $\begin{array}{c}\text { Cohesion } \\
(\mathrm{pa})\end{array}$ & Normal stiffness & Shear stiffness & $\begin{array}{c}\text { Friction an- } \\
\text { gle }\end{array}$ \\
\hline Slip surface & $2 \mathrm{e} 3$ & $2 \mathrm{e} 12$ & $2 \mathrm{e} 12$ & 10 \\
\hline
\end{tabular}

\section{Boundary Conditions}

Model boundary conditions model the bottom, front, back, left, right, five surface applied normal constraints, so that all five nodal plane to fixed rate is always zero, the top surface to the free surface.

\section{THE RESULTS}

\section{Displacement of piles analysis}

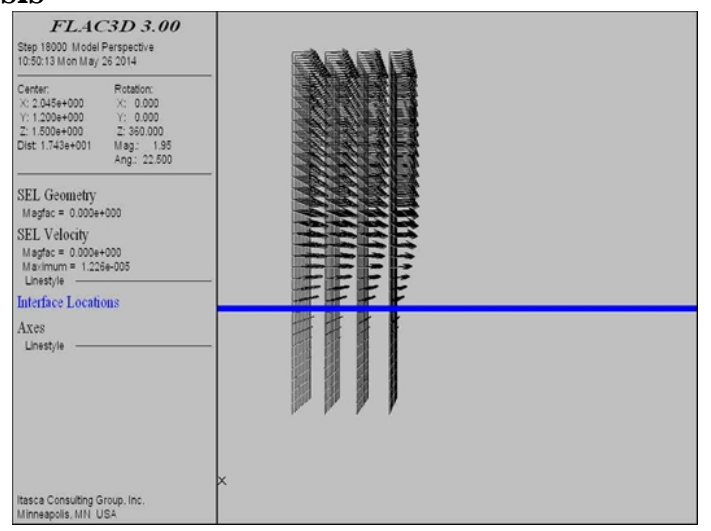

Figure 2.Displacement vector diagram of pile in simulation 1

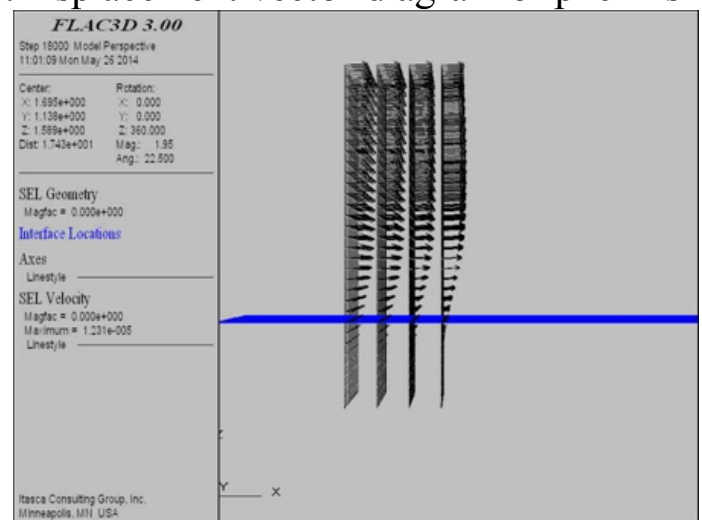

Figure 3.Displacement vector diagram of pile in simulation 2

From the graph, the displacement of the piles is basically the same, which indicates that the tie beam of the pile cap is very good to limit the displacement of the piles. When the embedded depth and free segment length ratio of 1:3,the micro-piles can play an anti sliding effect. 


\section{Bending moment analysis}

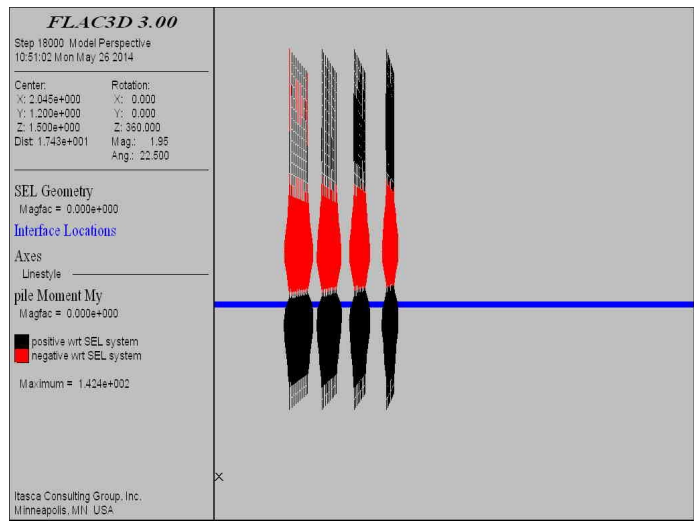

Figure 4 Bending moment of pile in simulation 1

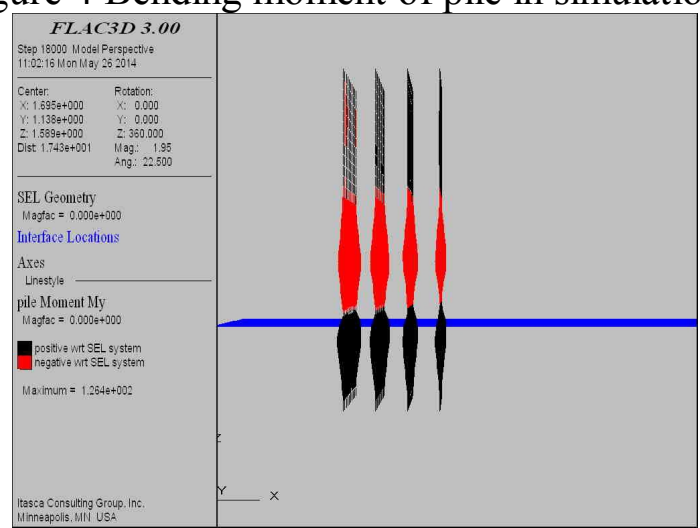

Figure 5 Bending moment of pile in simulation 2

From the graph, the maximum bending moment of the pile are located in near surface, micro pile structure design, need to near the slid surface of the pile were reinforced. Embedded depth and free segment length ratio of $1: 2.5$, the maximum bending moment is $0.142 \mathrm{kN} \cdot \mathrm{m}$, embedded depth and free segment length ratio of $1: 3$, the maximum bending moment is $0.126 \mathrm{kN} \cdot \mathrm{m}$, that is embedded solid when the pile depth of $1 / 4$ of the total length, micro piles can bear greater landslide thrust. From the first row to the fourth row of piles pile, bending moment was followed by a decreasing trend, indicating that acting on each row of piles of landslide thrust is to gradually decrease each row pile could be envisaged design strength Micropiling design not the same.

\section{Shear stress analysis}

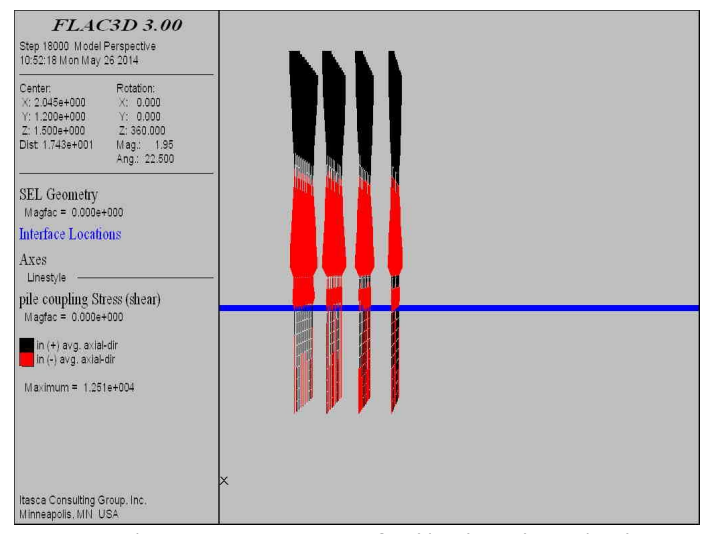

Figure 6 Shear stress of pile in simulation 1 


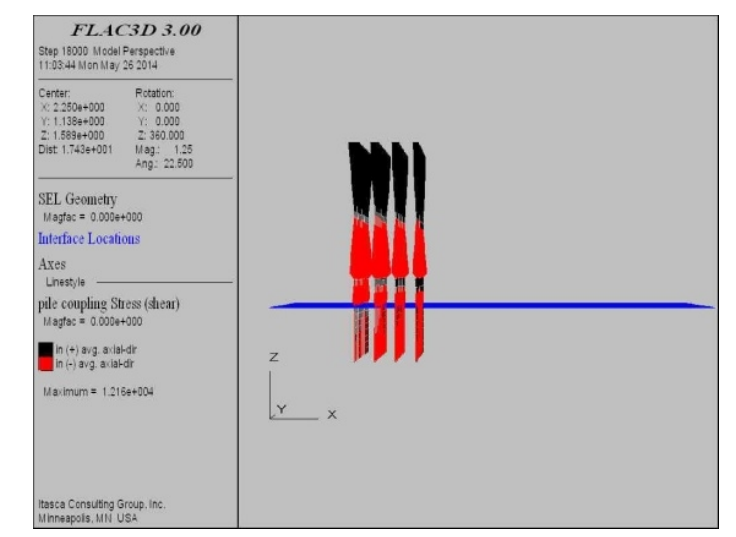

Figure 7 Shear stress of pile in simulation 2

From the graph, coupled shear stress pile concentrated in more free segment portion sliding surface, embedded depth only by a small shear stress, shear stress red portion is negative, indicating that the $\mathrm{X}$-forward, the black part of the shear stress is positive, show along the $\mathrm{X}$ negative. The maximum shear stress position is not located negative slip surfaces, but at a position approximately $1 / 8$ of the sliding surface above, this is due, at slip surfaces, in addition to the pile by the landslide thrust, but also at the same time by sliding surfaces and friction resistance effect of soil resistance before pile, which makes the force of the pile has been reduced; pile up along the slide surface friction resistance gradually decreases until it is zero, this time only by the landslide thrust pile and pile soil resistance before effect, causing the pile in a position above the slide surface appear positive maximum shear stress of about 1/8. Embedded depth and free segment length ratio of 1: 2.5, the maximum shear stress is $12.51 \mathrm{kPa}$, embedded depth and free segment length ratio of $1: 3$, the maximum shear should $12.16 \mathrm{kPa}$, that is, the total length of the pile embedded depth of $1 / 4$, better shear capacity.

\section{CONCLUSIONS}

Using FLAC $^{3 \mathrm{D}}$ program, the influence of two kinds of embedded depth on the mechanical properties of micro-pile composite structure is studied, which indicate that the maximum bending moment and shear stress of the pile are located in near surface, micro pile structure design, need to near the slid surface of the pile were reinforced. Embedded depth and free segment length ratio of 1:3, the displacement, shear stress and bending moment of micro-piles are relatively small, micro-pile composite structure can bear greater landslide thrust. micro-pile composite structure in the governance of sliding bed for bedrock and soil landslides, the main failure mode is near the sliding surface of the pile when bending and shearing failure occurs.

\section{REFERENCES}

[1] SUN Shu-wei, ZHU Ben-zhen, MA Hui-min. 2010. Model experimental research on anti-siding characteristics of mi-cropiles with cap beam[J]. Chinese Journal of Rock Mechanics and Engineering, 29(Supp. 1): 3039-3044.

[2] ZHU Bao-long, CHEN Qiang, WU Xi-yong. 2012. Centrifu-gal model test research on mechanical characteristics of mi-cropile groups reinforcing slope[J]. Journal of Sichuan Univer-sity (Engineering Science Edition), 44(2): 1-8.

[3] HU Yi-fu, WANG Ting-yong, MA Li. 2012. Research on an-ti-sliding characteristics of single double-row and composite anti-slide micropiles[J]. Chinese Journal of Rock Mechanics and Engineering, 31(7): 1499-1505.

[4] ZHANG Dan-dan, LIU Xiao-li, HUANG Min, et al. 2011. Finite element analysis on mechanical characteristics of mi-cropile group for rock slide reinforcement[J]. Journal of Engi-neering Geology, 19(Supp.): 502-507.

[5] FENG Jun, ZHOU De-pei, JIANG Nan, et al. 2006. A model for calculation of internal force of micropile system to reinforce bedding rock slope[J]. Chinese Journal of Rock Mechanics and Engineering, 25(2): $284-288$. 
[6] LIANG Jiong, MEN Yu-ming, SHI Sheng-wei. 2013. A model experiment on the steel reinforcement of micro-pile groups in landslide control[J]. Journal of Geological Hazards and Environment Preservation, 24(1):74-79.

[7] XIN Jian-ping, TANG Xiao-song, ZHENG Ying-ren, ZHANG Dong. 2015. Large-scale model tests of single-row and tri-ple-row anti-slide micropiles[J]. Rock and Soil Mechanics, $4(36): 1050-1055$

[8] Ardrew.Z.B. 2006. Load transfer in micropiles for slope stabi-lization from tests of large-scale physical models[D].University of Missouri-Columbia, 8-22,145-236

[9] Zhou Depei,Wang Huanlong,Sun Hongwei. 2009. Micro-pile composite structure and its design theory[J].Chinese Jour-nal of Rock Mechanics and Engineering,28 (7) : 1353 -1362.

[10] Su Yuanyuan. 2010. Model tests on grouted micro steel-tube composite pile in earth slope[D].Qingdao: Ocean University of China. 